\title{
Genetic Analysis of a Horizontal Resistance Locus BLMR2 in Brassica napus
}

\author{
Qiang Zhang ${ }^{\dagger}$, Hanna Dandena ${ }^{\dagger}$, Madison McCausland, Huizhi Liu, Zheng Liu, Wen Xu \\ and Genyi Li*
}

Department of Plant Science, University of Manitoba, Winnipeg, MB, Canada

OPEN ACCESS

Edited by:

Jacqueline Batley,

University of Western Australia,

Australia

Reviewed by:

Alexander ldnurm,

The University of Melbourne, Australia

Xiaodong Wang,

Jiangsu Academy of Agricultural

Sciences (JAAS), China

*Correspondence:

Genyi Li

genyi.li@ad.umanitoba.ca

tThese authors have contributed equally to this work and share first

authorship

Specialty section:

This article was submitted to

Plant Breeding,

a section of the journal

Frontiers in Plant Science

Received: 03 February 2021

Accepted: 12 April 2021

Published: 25 May 2021

Citation:

Zhang $Q$, Dandena $H$,

McCausland M, Liu H, Liu Z, Xu W and Li G (2021) Genetic Analysis of a Horizontal Resistance Locus BLMR2

in Brassica napus.

Front. Plant Sci. 12:663868.

doi: 10.3389/fp/s.2021.663868
Leptosphaeria maculans causes blackleg disease in Brassica napus. The blackleg disease is mainly controlled by resistance genes in $B$. napus. Previous studies have shown that the blackleg resistant BLMR2 locus that conferred horizontal resistance under field conditions, is located on chromosome A10 of $B$. napus. The purpose of this study is to fine map this locus and hence identify a candidate gene underlying horizontal resistance. The spectrum of resistance to $L$. maculans isolates of the resistance locus $B L M R 2$ was analyzed using near isogenic lines, resistant, and susceptible cultivars. The results showed that this locus was horizontally resistant to all isolates tested. Sequence characterized amplified regions (SCAR), simple sequence repeats (SSR), and single nucleotide polymorphism (SNP) markers were developed in the chromosome region of BLMR2 and a fine genetic map was constructed. Two molecular markers narrowed $B L M R 2$ in a $53.37 \mathrm{~kb}$ region where six genes were annotated. Among the six annotated genes, BnaA10g11280D/BnaA10g11290D encoding a cytochrome P450 protein were predicted as the candidate of BLMR2. Based on the profiling of pathogen induced transcriptome, three expressed genes in the six annotated genes were identified while only cytochrome P450 showed upregulation. The candidate corresponds to the gene involved in the indole glucosinolate biosynthesis pathway and plant basal defense in Arabidopsis thaliana. The molecular markers identified in this study will allow the quick incorporation of the BLMR2 allele in rapeseed cultivars to enhance blackleg resistance.

Keywords: Brassica napus, Leptosphaeria maculans, BLMR2, cytochrome p450, fine mapping

\section{INTRODUCTION}

Brassica napus (oilseed rape/canola) is an important crop used for edible oil production worldwide. Blackleg, caused by Leptosphaeria maculans, is one of the most devastating diseases in B. napus (canola, oilseed, and rapeseed) production. There are both qualitative and quantitative types of resistance to fungal pathogens like L. maculans (Rouxel et al., 2003; Raman et al., 2012, 2013). 
Qualitative resistance is race-specific and depends on the presence of a single resistance (R) gene in plant and corresponding avirulence (Avr) genes in pathogen (AnsanMelayah et al., 1998). In contrast, quantitative resistance or horizontal resistance is race non-specific, which may be mediated by several genes and expressed from the seedling to adult plant stages, conferring only partial resistance to all races of the pathogen (Delourme et al., 2006; Rimmer, 2006). Identification and incorporation of resistance genes in Brassica species to produce resistant cultivars is an efficient approach to combat blackleg disease in B. napus (Hayward et al., 2012).

To date, over a dozen loci including Rlm1-10, LepR1 to LepR4, $B L M R 1$, and BLMR2 conferring resistance to L. maculans have been mapped in the cultivated Brassica species (Yu et al., 2005, 2008, 2013; Delourme et al., 2006; Rimmer, 2006; Long et al., 2011; Larkan et al., 2013). However, the effectiveness of these resistance genes is decreased after they are used in production for a few years, and the genes need to be replaced with other novel genes (Li et al., 2003; Rouxel et al., 2003; Kutcher et al., 2007). For example, LepR 3 in Surpass 400 that provides racespecific resistance to the fungal pathogen $L$. maculans suffered a major defeat in Australia in 2004 (Li et al., 2003; Sprague et al., 2006). On the other hand, studies on rice (Maeda et al., 2006) and barley (Van Berloo et al., 2001) have confirmed that quantitative genes conferred effective resistance. Quantitative resistance likely remains effective over time than qualitative resistance (Kaur et al., 2009; Brun et al., 2010; Zhang et al., 2016). Therefore, it is important and necessary to identify and combine qualitative and quantitative genes for durable blackleg resistance.

It is very difficult to identify the genes for quantitative trait loci in the complex genome of $B$. napus because little information is available on the genetic control of quantitative resistance to L. maculans. In previous study, the blackleg quantitative resistance gene BLMR2 identified in Surpass 400 showed horizontal resistance under field conditions (Dandena et al., 2019). A few blackleg resistance genes including $R \operatorname{lm} 2$, LepR3, BLMR2, and LepR2 have been mapped on B. napus chromosome A10. Among these the highly resistant Rlm2 and LepR3 are allelic and function as receptors (Larkan et al., 2013, 2014, 2015). Characterization of the BLMR2 and LepR2 need further studies although these genes are likely different from the other $\mathrm{R}$ genes based on the map position and phenotype (Long et al., 2011; Larkan et al., 2016). BLMR2 segregated as a single dominant allele and has a distinctly intermediate phenotype when cotyledon inoculated with the L. maculans isolate 8741 (Long et al., 2011). This allowed the development of NILs (W + BLMR2) using molecular marker assisted backcrossing along with progeny testing of recombinants.

In this report, BLMR2 was fine mapped in B. napus with the use of sequence characterized amplified regions (SCAR) and simple sequence repeats (SSR) markers. Furthermore, inoculation assay with individual isolates showed that $B L M R 2$ has race non-specific resistance to all the isolates tested. These results lay a foundation for utilizing the blackleg resistance BLMR2 allele in developing resistant $B$. napus cultivars that effectively control L. maculans.

\section{MATERIALS AND METHODS}

\section{Materials for Testing Horizontal Resistance}

Three near isogenic lines containing resistance $B L M R 1, B L M R 2$, and $R \operatorname{lm} 2$ alleles were developed using the two resistant cultivars Surpass 400 and Glacier, and a susceptible cultivar Westar. $B L M R 1$ and BLMR2 were derived from the cross between Surpass 400 and Westar (Long et al., 2011) while Rlm2 was derived from the cross between Glacier and Westar. BLMR1 and $B L M R 2$ were separated at BC1F3 based on differential phenotypic interaction with the L. maculans isolate 87-41 and molecular marker data (Long et al., 2011). From crosses of Surpass $400 \times$ Westar and Glacier $\times$ Westar, F3 and F1 progeny, respectively, were backcrossed to Westar four to five times and molecular marker assisted selection (MAS) was implemented during backcrossing (Dandena et al., 2019). Individuals containing homozygous $B L M R 1, B L M R 2$, or $R \operatorname{lm} 2$ alleles were selected based on molecular markers and inoculation assays to obtain three isogenic lines in Westar background, named as $\mathrm{W}+\mathrm{BLMR} 1\left(\mathrm{BC}_{4} \mathrm{~F}_{4}\right), \mathrm{W}+\mathrm{BLMR} 2\left(\mathrm{BC}_{4} \mathrm{~F}_{4}\right)$, and $\mathrm{W}+\mathrm{Rlm} 2\left(\mathrm{BC}_{4} \mathrm{~F}_{2}\right)$, respectively. The near isogenic lines, together with two resistant cultivars Glacier and Quinta, and the susceptible Westar were used to perform interaction analysis.

\section{Mapping Populations}

The $\mathrm{BC}_{1} \mathrm{~F}_{3}$ plants carrying $B L M R 2 /$ blmr2 alleles from the cross of $B$. napus cultivar Surpass 400 and Westar were backcrossed to Westar (blmr2/blmr2) to produce $\mathrm{BC}_{2}, \mathrm{BC}_{3}$, and $\mathrm{BC}_{4}$ populations, and the $\mathrm{BC}_{4}$ was selfed to obtain $\mathrm{BC}_{4} \mathrm{~F}_{4}$. All plants used in backcrossing and selfing were phenotyped through inoculation and genotyped using the flanking molecular markers. The $\mathrm{BC}_{4} \mathrm{~F}_{3}$ and $\mathrm{BC}_{4} \mathrm{~F}_{4}$ were inoculated with L. maculans isolate 87-41 to test cotyledon resistance. Segregation ratios of resistant to susceptible individuals in the $\mathrm{F}_{4}$ and $\mathrm{BC}_{4}$ were analyzed with $\chi 2$ test of goodness of fit. A total of 5,952 $\mathrm{BC}_{3}$ individuals were used to fine map the resistance locus.

\section{Preparation of L. maculans Inoculum}

To test the horizontal and race-non-specific resistance of BLMR2, 24 L. maculans isolates were used in cotyledon assay. These pathogen isolates were selected from the collection at the University of Manitoba. The inoculum of all isolates was prepared, and cotyledons were wounded and inoculated as described previously (Long et al., 2011). Disease reactions were rated in 12-16 days after inoculation according to the classification of 0-9 (Chen and Fernando, 2006).

\section{DNA Extraction and Development of SSR and SCAR}

A modified CTAB extraction procedure as described by Li and Quiros (2001) was used to extract DNA. The Brassica rapa genomic sequence ${ }^{1}$ was used to identify SSR loci and primers covering SSR were designed to amplify the specific loci in

\footnotetext{
${ }^{1}$ http://brassicadb.cn
} 
B. napus. SCAR loci were developed using a similar procedure as SSR markers except sequencing the targets from Surpass 400 and Westar. The A genome-specific primers were used to amplify Surpass 400 and Westar to identify insertions/deletions of the targets which were used to develop SCAR markers.

\section{Detection of SCAR and SSR}

A five fluorescent dye color set 6-FAM, VIC, NED, PET and LIZ was used for signal detection with an ABI 3100xl Genetic Analyzer (Thermo Fisher Scientific, Toronto, ON, Canada). The LIZ color was the standard and other four were used to label primers of SSR and SCAR. For SSR and SCAR detection, the genome-specific primers were used to obtain PCR products containing SSR or deletion/insertion positions. A $10 \mu \mathrm{l}$ PCR mixture contained two genome-specific primers and one labeled M13 primer, $50 \mathrm{ng}$ of genomic DNA, $0.375 \mathrm{mM}$ dNTP, 1X PCR buffer, $1.5 \mathrm{mM} \mathrm{MgCl} 2$ and $1 \mathrm{U}$ of Taq polymerase. The PCR running program was $94^{\circ} \mathrm{C}, 3 \mathrm{~min} ; 94^{\circ} \mathrm{C}, 1 \mathrm{~min} ; 58^{\circ} \mathrm{C}$ with $-0.8^{\circ} \mathrm{C}$ each cycle $1 \mathrm{~min}$ and $72^{\circ} \mathrm{C}, 1 \mathrm{~min}$ for 5 cycles; $94^{\circ} \mathrm{C}, 1 \mathrm{~min} ; 57^{\circ} \mathrm{C}, 1 \mathrm{~min}$ and $72^{\circ} \mathrm{C}, 1 \mathrm{~min}$ for 25 cycles. The PCR products were separated in the ABI 3100 Genetic analyzer. The data were collected and analyzed with ABI GenScan

TABLE 1 | Primers for all applications.

\begin{tabular}{|c|c|c|}
\hline Primer names & Sequence $\left(5^{\prime}-3^{\prime}\right)$ & Applications \\
\hline N10-56 & TAATACTGGTTAATTATGCT & Mapping \\
\hline RN10-56 & ACAGTACATTCACGTTCTAG & Mapping \\
\hline N10-47 & ACTGGCCTATGGATGACGTT & Mapping \\
\hline RN10-47 & AATCCAGCAGTAGACCCCAT & Mapping \\
\hline N10BA & CGAAAGTAAGAAGAGCAAGA & Mapping \\
\hline N10BB & GATACTCTAGTTGTTGACAA & Mapping \\
\hline N10-45 & CAGAAGAAGAAGGATATGGT & Mapping \\
\hline RN10-45 & TCCAGTTAACCAATGCTGGT & Mapping \\
\hline N10-43 & CTAAGAAATTTCCTATGACAC & Mapping \\
\hline RN10-43 & TTGTCAATGTCTCATGCTAA & Mapping \\
\hline N10-39 & GGCTGCGTTGTTTCATACCT & Mapping \\
\hline N10-39 & ATGTGGGAGCTGAGGTTGTC & Mapping \\
\hline RN10-39 & GTCCTTAGTTGGTCCACTGT & Mapping \\
\hline N10-34 & CGAGCAGCAAATCCATATCC & Mapping \\
\hline RN10-34 & CAATITTGTATTITCTTATGGAAACTG & Mapping \\
\hline N10-38 & TTCAACATTTCTCCGCGATA & Mapping \\
\hline RN10-38 & ТTCCATCTGCTTCCACCTAA & Mapping \\
\hline N10-37 & CAGTCCTGACTTTGCCATCA & Mapping \\
\hline N10-37 & ACAGGCGAGAGGTTGAAGA & Mapping \\
\hline N10-40 & CACAATTTCTGGTATACAGATTG & Mapping \\
\hline RN10-40 & CTाTGGAGCGAATTGTTGAAG & Mapping \\
\hline 10BM1 & TGCAGGCAATTATTTCAGTGG & MAS \\
\hline 10BM2 & AGCTTATGTTAGGTGGAAG & MAS \\
\hline HN62F & ATGGATTACATTTGCTCTTATTG & TA cloning \\
\hline HN65R & TTAAGCCAAAAGATTAGTCATA & TA cloning \\
\hline ACTIN-1F & CGATGGTGAGGACATTCAGC & RT-PCR \\
\hline ACTIN-1R & AGAGAGAAAGAACAGCCTGGAT & RT-PCR \\
\hline MM1F & ACAAGTAGACCAACCCAA & RT-PCR \\
\hline MM1R & CCACAAACTCGCCATCGC & RT-PCR \\
\hline
\end{tabular}

software and further transferred into images for scoring using Genographer software.

\section{Sequencing of the Candidate Gene}

Fully expanded cotyledons were inoculated using $L$. maculans isolate 87-41 (isolate-inoculated) or water (mock-inoculation). Four days after inoculation, cotyledon samples from eight individual plants per sample were pooled and ground in liquid nitrogen. Total RNA was extracted using Trizol reagent (Thermo Fisher Scientific, Toronto, ON, Canada). RNA quality was determined using $1 \%$ agarose gel and Nanodrop. cDNA was synthesized using total RNA and the SuperScript ${ }^{\mathrm{TM}}$ III kit following manufacturer's protocol (Thermo Fisher Scientific, Toronto, ON, Canada). Then, primers (Table 1) were used to amply the full-length cDNA of the candidate gene of BLMR2 and cloned into the TA cloning vector with the TOPO ${ }^{\circledR} \mathrm{TA}$ Cloning ${ }^{\circledR}$ Kit (Thermo Fisher Scientific, Toronto, ON, Canada). Positive clones were selected to extract plasmid DNA using the standard mini preparation protocol. The plasmid DNA was sequenced using the BigDye ${ }^{\mathrm{TM}}$ terminator v3.1 cycle sequencing kit (Thermo Fisher Scientific, Toronto, ON, Canada). Full length cDNA sequence was assembled using SeqMan software.
TABLE 2 | Testing of resistance spectra of three near isogenic lines and three cultivars in Brassica napus using 24 isolates of Leptosphaeria maculans*.

\begin{tabular}{|c|c|c|c|c|c|c|}
\hline Isolates & $\begin{array}{c}\text { W + } \\
\text { BLMR2 }\end{array}$ & $\begin{array}{c}\text { W + } \\
\text { BLMR1 }\end{array}$ & $\begin{array}{l}\text { W + } \\
\text { RIm2 }\end{array}$ & Glacier & Quinta & Westar \\
\hline $87-1$ & $\mathrm{R}$ & S & $\mathrm{S}$ & S & S & S \\
\hline M4-1 & $\mathrm{R}$ & S & S & S & S & S \\
\hline M4-2 & $\mathrm{R}$ & $S$ & $\mathrm{~S}$ & $S$ & $S$ & $S$ \\
\hline 10Aridries-dk & $\mathrm{R}$ & S & S & S & $R$ & S \\
\hline $3-12-01$ & $\mathrm{R}$ & S & $\mathrm{R}$ & S & $\mathrm{R}$ & S \\
\hline 08-01-05 & $\mathrm{R}$ & S & $\mathrm{R}$ & S & $\mathrm{R}$ & S \\
\hline 9STONEWALL & $\mathrm{R}$ & S & $\mathrm{R}$ & S & $\mathrm{R}$ & S \\
\hline $3-15-03$ & $\mathrm{R}$ & S & $\mathrm{R}$ & $\mathrm{R}$ & $\mathrm{R}$ & S \\
\hline 6NBW-01 & $\mathrm{R}$ & S & $\mathrm{R}$ & $\mathrm{R}$ & $\mathrm{R}$ & S \\
\hline $89-3$ & $\mathrm{R}$ & S & $\mathrm{R}$ & $\mathrm{R}$ & $\mathrm{R}$ & S \\
\hline ND04-05-01 & $\mathrm{R}$ & S & $\mathrm{R}$ & $\mathrm{R}$ & $\mathrm{R}$ & S \\
\hline $86-12$ & $\mathrm{R}$ & S & $\mathrm{R}$ & $\mathrm{R}$ & $\mathrm{R}$ & S \\
\hline 4-09-109 & $\mathrm{R}$ & $\mathrm{R}$ & S & $\mathrm{R}$ & S & S \\
\hline 7-02-01 & $\mathrm{R}$ & $\mathrm{R}$ & $S$ & $\mathrm{R}$ & $S$ & S \\
\hline $53-31$ & $\mathrm{R}$ & $\mathrm{R}$ & S & $\mathrm{R}$ & $S$ & S \\
\hline Lifolle & $\mathrm{R}$ & $\mathrm{R}$ & S & $\mathrm{R}$ & S & S \\
\hline PL03-02-01 & $\mathrm{R}$ & $\mathrm{R}$ & $S$ & $\mathrm{R}$ & $S$ & S \\
\hline PL03-42-06 & $\mathrm{R}$ & $\mathrm{R}$ & S & $\mathrm{R}$ & $S$ & S \\
\hline $3-54-01$ & $\mathrm{R}$ & $R$ & $S$ & $\mathrm{R}$ & $\mathrm{R}$ & S \\
\hline $4-09-01$ & $\mathrm{R}$ & $\mathrm{R}$ & $\mathrm{S}$ & $\mathrm{R}$ & $\mathrm{R}$ & S \\
\hline 3-01-Roland & $\mathrm{R}$ & $R$ & $S$ & $\mathrm{R}$ & $\mathrm{R}$ & S \\
\hline $4-09-107$ & $\mathrm{R}$ & $\mathrm{R}$ & $\mathrm{R}$ & $\mathrm{R}$ & $\mathrm{R}$ & S \\
\hline $87-41$ & $\mathrm{R}$ & $R$ & $\mathrm{R}$ & $\mathrm{R}$ & $\mathrm{R}$ & S \\
\hline Lifolle 5 & $\mathrm{R}$ & $\mathrm{R}$ & $\mathrm{R}$ & $S$ & $\mathrm{R}$ & S \\
\hline
\end{tabular}

${ }^{*}$ All isolates from the collection of University of Manitoba. Three near isogenic lines $W+B L M R 1, W+B L M R 2, W+R I m 2$, two resistant cultivars Glacier and Quinta, and susceptible cultivar Westar; $R$ representing $0-4$ ratings, $S$ representing 59 ratings. 


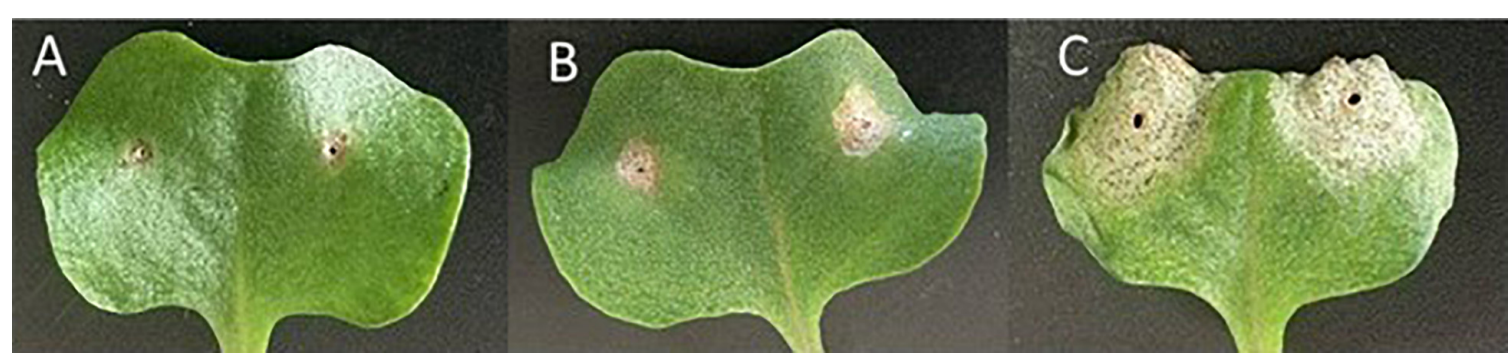

FIGURE 1 | Cotyledons of Surpass 400, near isogenic line W + BLMR2 and Westar, 14 days after inoculation (dai) of the pycnidiospore suspension $\left(2 \times 10^{7}\right.$ spores $/ \mathrm{mL}$ ) of Leptosphaeria maculans isolate 87-41. Surpass 400 showing high resistance (A); W + BLMR2 showing intermedium resistance (B); and Westar with the susceptible phenotype (C).

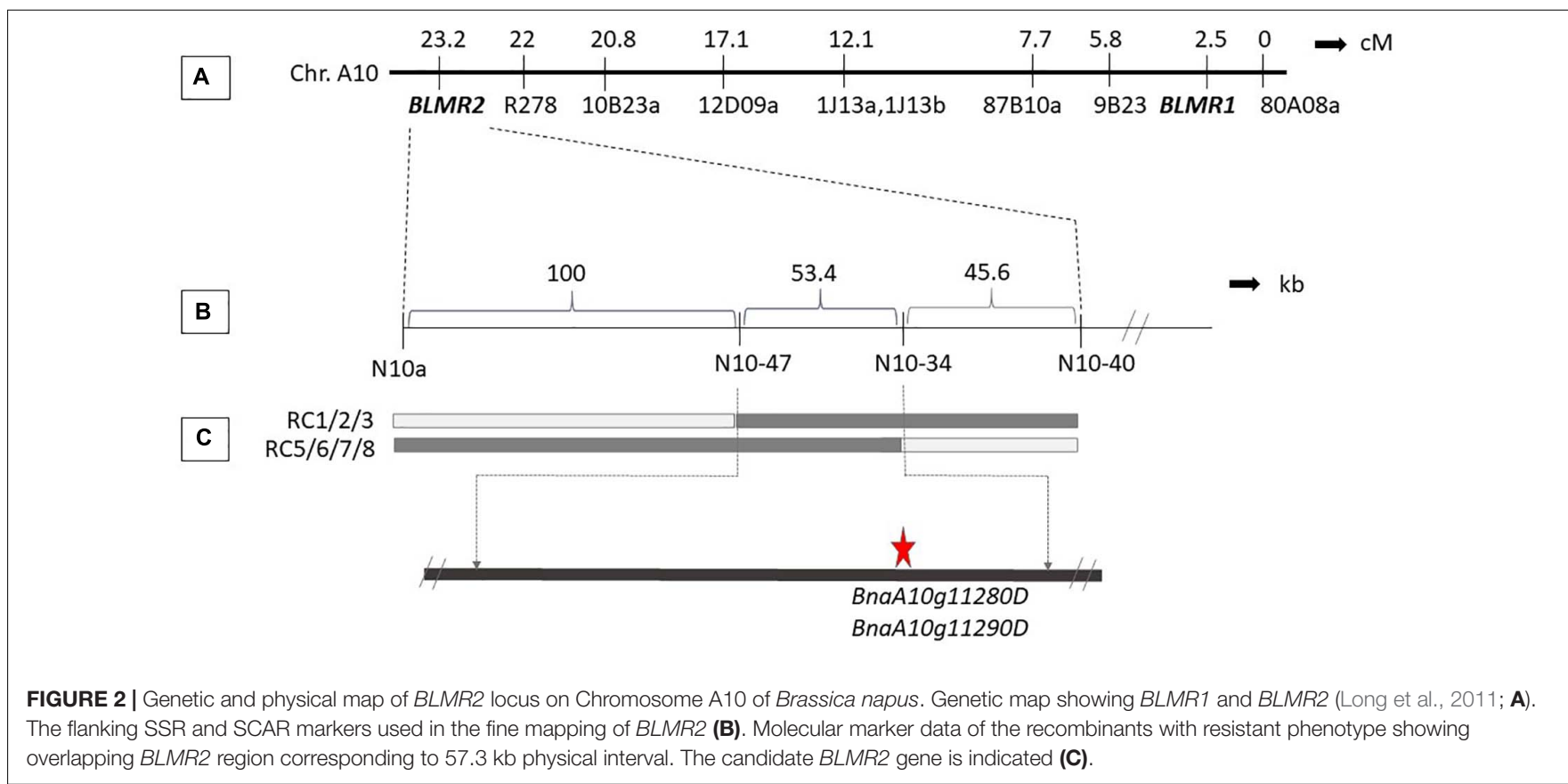

\section{Quantitative Analysis of Candidate Gene Expression}

Total RNA was extracted from cotyledon samples of NIL, $\mathrm{W}+\mathrm{BLMR} 2$ and Westar inoculated with $L$. maculans isolate 8741 at 4 days after inoculation (dai). cDNA was synthesized using the SuperScript IV First-Strand Synthesis kit (Thermo Fisher Scientific, Toronto, ON, Canada). Quantitative real-time PCR (qRT-PCR) was conducted using SYBR Green Master Mix (BioRad) according to manufacturer's recommendation (Bio-Rad). The P450 gene specific primers were used to amplify the gene (Table 1). The actin gene (BnaA01g19850D) was used as a control for normalization. Relative gene expression was calculated by the $2^{-\Delta \Delta \mathrm{CT}}$ method.

\section{RESULTS}

\section{Resistance to L. maculans Isolates}

Three near isogenic lines $\mathrm{W}+$ BLMR1, W + BLMR2, and $\mathrm{W}+\mathrm{Rlm} 2$, along with Wester, Glacier, and Quinta were inoculated with 24 isolates. The results showed that only
$\mathrm{W}+$ BLMR2 was resistant to all tested isolates, indicating that the resistance of $B L M R 2$ was horizontal and race non-specific. $B L M R 1$ and $R \operatorname{lm} 2$ showed differential interactions with the tested isolates and the two resistant cultivars Glacier and Quinta also showed different resistant spectra while Westar was susceptible to all isolates as expected (Table 2).

\section{Segregation of BLMR2 in the Mapping Populations}

In the mapping populations of $B L M R 2,656 \mathrm{~F}_{4}$ individuals were used to confirm the segregation ratio of BLMR2. There were 513 resistant plants and 143 susceptible plants showing a 3:1 segregation ratio $\left(\chi^{2}\right.$ test, $\left.p>0.05\right)$. In the $\mathrm{BC}_{4}$ mapping population of 831 individuals, there were 438 resistant plants and 393 susceptible plants showing a 1:1 segregation ratio $\left(\chi^{2}\right.$ test, $p>0.05)$, suggesting that one dominant resistance allele is responsible for the BLMR2 resistance to blackleg (Figure 1).

\section{Fine Mapping of the Resistance Gene}

Sequence characterized amplified region (SCAR) and SSR markers were used to map BLMR2 on chromosome A10. Using 
1,632 $\mathrm{BC}_{4}$ plants, six recombinant individuals were obtained. Their selfed progeny was inoculated with L. maculans isolate 87-41 to confirm recombinants. Then, more sequence-based SCAR and SSR were developed to fine map the BLMR2 locus. Another 4,320 $\mathrm{BC}_{4}$ individuals were inoculated with L. maculans isolate 87-41 to identify another 14 recombinants. Using all 20 recombinants, $B L M R 2$ was narrowed in a small region between molecular markers N10-47 and N10-43 after their phenotypes and genotypes were analyzed (Table 3 and Figure 2). Selfed progeny of all recombinants was also tested to confirm the recombination in the $\mathrm{BC}_{4} \mathrm{~F}_{4}$. The chromosome region of molecular markers N10-47 and N10-43 was located from 9494993 to 9548367 in the reference genome sequence of chromosome $\mathrm{A}_{10}{ }^{2}$, spanning a $53.37 \mathrm{~kb}$ region. In the reference sequence, seven genes are annotated while two genes BnaA10g11280D and BnaAlog11290D were re-annotated into one gene based on the full length of cDNA.

Full length cDNA of the candidate gene was sequenced from both the near isogenic line $\mathrm{W}+\mathrm{BLMR} 2$ with BLMR2 in Westar background and Westar. Comparison of the cDNA sequences showed that there are six polymorphisms in W + BLMR2 compared to the background genotype Westar while only one of these six nucleotide changes results in one difference of amino acid (AA) (Supplementary Data 1). RNA-seq data in the previous report (NCBI Archive under the BioProject accession number PRJNA378851, Zhou et al., 2019) were analyzed to compare the expression of the six genes in the fine mapped region of $B L M R 2$ and the results showed that three of the six genes were expressed while only the candidate gene was upregulated after inoculation (Supplementary Data 2).

\section{Analysis of Expression of the Candidate Gene by qPCR}

In addition, qRT-PCR was used to determine the relative gene expression of the candidate gene in the resistant $\mathrm{W}+\mathrm{BLMR} 2$ and Westar. The relative fold change in the accumulation of $B$. napus CYP450 transcript was significantly higher in the pathogen (L. maculans isolate 87-41) inoculated resistant W + BLMR2 at 4 dai compared to pathogen inoculated Westar or mock checks (Figure 3). Our results suggest that CYP450 possibly plays a role in L. maculans induced defense response in B. napus.

\section{DISCUSSION}

It is hypothesized that quantitative resistance genes work by a complex interaction of many response genes to pathogens, and any individual gene does not show strong effect, therefore there is less selective pressure on the fungus (Zhu et al., 1993; Delourme et al., 2008). Mapping and eventually cloning these genes will facilitate the transfer and pyramiding of multiple resistance genes with different resistance spectra through molecular markerassisted selection in B. napus (Long et al., 2011). In this paper, the disease reactions of $B L M R 2$ to a range of isolates of L. maculans were analyzed. The results showed that BLMR2 is

${ }^{2}$ www.genoscope.cns.fr

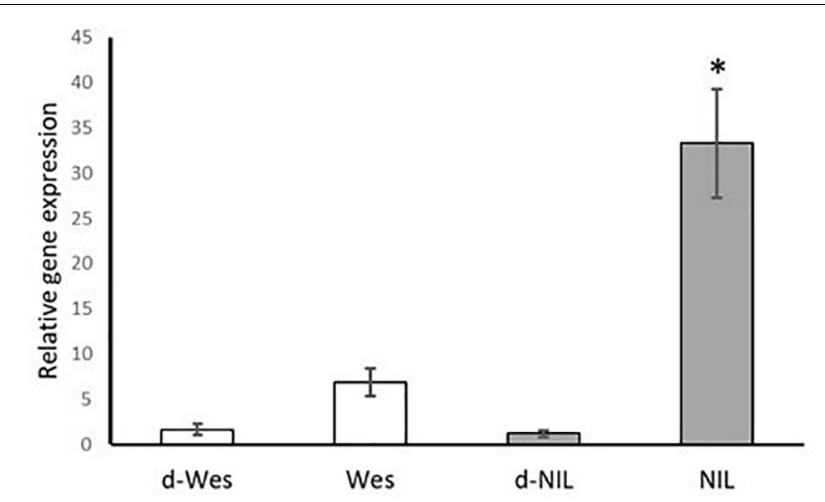

FIGURE 3 | Validation of the expression of Brassica napus CYP81F2 gene in the resistant near isogenic line (NIL) W + BLMR2 and susceptible Westar using qRT-PCR at 4 days after inoculation (dai) with Leptosphaeria maculans isolate 87-41. Samples d-Wes is water check of Westar; Wes, inoculated Westar; d-NIL, water check of NIL; NIL, inoculated NIL. The relative gene expression value is normalized using the Actin gene (BnaA01g19850D). Error bar shows standard deviation of the mean based on three biological replicates. The asterisk $\left({ }^{*}\right)$ represents significant difference from all the other samples based on Tukey test, $p<0.05$.

a horizontal resistance locus to all the isolates of the blackleg pathogen, compared to typical $\mathrm{R}$ genes and resistant cultivars. In the previous study, the results in field testing showed that $B L M R 2$ conferred resistance to blackleg under field conditions, suggesting that this resistance gene is very useful to the breeding of resistant cultivars in B. napus (Dandena et al., 2019).

In this study, BLMR2 was fine mapped in a $53.37 \mathrm{~kb}$ region where six genes were annotated. Of these six genes, one was identified as the candidate gene of BLMR2 based on the analysis of gene expression. The candidate is homologous to CYP81F2 in Arabidopsis thaliana. Several studies showed that CYP81F2 catalyzes the modification of indole glucosinolate (IGS) which involves the accumulation of defensive secondary metabolites (Abdel-farid et al., 2010; Wiesner et al., 2013). In Arabidopsis, its hydrolytic products produced by myrosinases (PEN2 and PEN3) are involved in innate immune response to pathogens (Bednarek et al., 2009; Clay et al., 2009). The CYP81F2 and PEN2 dependent hydrolytic products are also associated with callose deposition in FLG22-triggered basal immunity (Bednarek et al., 2009; Clay et al., 2009). While it remains elusive whether genes involving the glucosinolate biosynthesis are linked to defense response induced by L. maculans in B. napus, a complex pattern of IGS accumulation in B. rapa - L. maculans interaction was observed (Abdel-farid et al., 2010). Furthermore, Robin et al. (2017) associated upregulation of CYP81F2 (Bol026044) gene in the moderate blackleg resistant cabbage cultivar with increased IGS accumulation at the seedling stage. Recent global transcriptomic studies identified multiple genes involved in the IGS biosynthesis in B. napus - L. maculans incompatible interaction (Becker et al., 2017; Zhou et al., 2019). However, the mechanisms underlying horizontal resistance are rarely reported, and hence the findings in this study suggest that secondary metabolic pathways such as the biosynthetic pathways of glucosinolates may play a role in 
TABLE 3 | Phenotypesand genotypes of 20 recombinants in the $\mathrm{BC}_{3}$ population of Brassica napus*.

\begin{tabular}{|c|c|c|c|c|c|c|c|c|c|c|c|c|}
\hline Recombinant & Phenotype & N10a & N10-56 & N10-47 & N10b & N10-45 & N10-43 & N10-39 & N10-34 & N10-37 & N10-38 & N10-40 \\
\hline $\mathrm{RC} 01$ & $\mathrm{R}$ & A & $A$ & $A B$ & $A B$ & $A B$ & $A B$ & $A B$ & $A B$ & $A B$ & $A B$ & $\mathrm{AB}$ \\
\hline $\mathrm{RCO} 2$ & $\mathrm{R}$ & A & $A$ & $A B$ & $A B$ & $A B$ & $A B$ & $A B$ & $A B$ & $A B$ & $A B$ & $A B$ \\
\hline RCO3 & $\mathrm{R}$ & A & A & $A B$ & $A B$ & $A B$ & $A B$ & $A B$ & $A B$ & $A B$ & $A B$ & $A B$ \\
\hline RCO4 & $\mathrm{R}$ & $A B$ & $A B$ & $A B$ & $A B$ & $A B$ & $A B$ & $A B$ & $A B$ & $A B$ & $A B$ & $A B$ \\
\hline RC05 & $\mathrm{R}$ & $A B$ & $A B$ & $A B$ & $A B$ & $A B$ & $A B$ & $A B$ & $A B$ & $A$ & $A$ & $A$ \\
\hline RC06 & $\mathrm{R}$ & $A B$ & $A B$ & $A B$ & $A B$ & $A B$ & $A B$ & $A B$ & $A B$ & A & $A$ & A \\
\hline RCO7 & $\mathrm{R}$ & $A B$ & $A B$ & $A B$ & $A B$ & $A B$ & $A B$ & $A B$ & $A B$ & A & $A$ & A \\
\hline RC08 & $\mathrm{R}$ & $A B$ & $A B$ & $A B$ & $A B$ & $A B$ & $A B$ & $A B$ & $A B$ & A & $A$ & A \\
\hline RC09 & $\mathrm{S}$ & $A$ & $A$ & $A$ & $A$ & $A$ & $A B$ & $A B$ & $A B$ & $A B$ & $A B$ & $A B$ \\
\hline $\mathrm{RC} 10$ & S & $A$ & $A$ & $A$ & $A$ & A & A & $A B$ & $A B$ & $A B$ & $A B$ & $A B$ \\
\hline $\mathrm{RC} 11$ & $\mathrm{~S}$ & A & A & A & A & $A$ & A & $A$ & $A B$ & $A B$ & $A B$ & $A B$ \\
\hline RC12 & $\mathrm{S}$ & A & A & A & A & $A$ & A & A & $A B$ & $A B$ & $A B$ & $A B$ \\
\hline $\mathrm{RC} 13$ & $S$ & A & $A$ & A & $A$ & A & $A$ & $A$ & $A B$ & $A B$ & $A B$ & $A B$ \\
\hline RC14 & S & A & $A$ & A & A & $A$ & A & A & $A$ & $A B$ & $A B$ & $A B$ \\
\hline RC15 & S & A & $A$ & A & A & $A$ & A & A & A & $A B$ & $A B$ & $A B$ \\
\hline $\mathrm{RC} 16$ & $S$ & A & $A$ & A & $A$ & A & A & $A$ & A & $A B$ & $A B$ & $A B$ \\
\hline $\mathrm{RC} 17$ & $S$ & A & $A$ & $A$ & $A$ & $A$ & $A$ & $A$ & A & $A B$ & $A B$ & $A B$ \\
\hline RC18 & $S$ & $A$ & $A$ & $A$ & A & $A$ & A & A & A & $A$ & $A B$ & $A B$ \\
\hline RC19 & S & $A B$ & $A B$ & $A B$ & A & $A$ & A & A & A & A & $A$ & $A$ \\
\hline RC20 & S & $A B$ & $A B$ & $A B$ & $A$ & $A$ & $A$ & $A$ & A & $A$ & $A$ & $A$ \\
\hline
\end{tabular}

${ }^{*} R$, resistance; $S$, susceptible phenotype; $A$, genotype of Westar; $A B$, heterozygous genotypes (B, genotype of BLMR2 in Surpass 400$)$.

plant resistance to various diseases. However, how the change of AA in the DNA sequence confers the horizontal resistance in this study need to be investigated in the future.

Plant disease resistance is classified in many ways, vertical vs horizontal, qualitative vs quantitative, race-specific vs racenon-specific, a high vs an intermediate level of resistance. Typical R genes such as NBS-LRR, receptor like proteins (RLP) and receptor like kinases (RLK) have been cloned since their phenotypes can be easily observed (Dangl and Jones, 2001). For some diseases such as sclerotinia diseases in rapeseed, sunflower and soybean and fusarium head blight in cereal crops, no vertical, qualitative or race-specific resistance has been identified so no typical R genes for these diseases has been cloned (Behla et al., 2017; Mesterhazy, 2020). In this study, the horizontal resistance of BLMR2 has been stressed since it conferred intermediate resistance under field conditions (Dandena et al., 2019) and showed intermediate resistance to all isolated tested under controlled environmental conditions. Several characteristics of the resistance of the $B L M R 2$ locus need to be addressed. First, its resistance is race-non-specific and intermediate while the resistance is dominant and resistant in all heterozygous genotypes tested. Second, single allele of this locus confers relatively strong resistance, so the phenotypes of this locus were relatively easy to be scored (Figure 1). The accurate scores of phenotypes made it possible to perform fine mapping and narrow the gene into a small chromosome region. Third, this kind of resistance is assumed to be controlled by polygenes and very difficult to be transferred from cultivar to cultivar while the BLMR2 locus can be easily transferred using molecular markers targeting the six mutations in the DNA sequence (Supplementary Data 1). Finally, unlike all previous reports where horizontal resistance is hypothesized to have a minor effect of one locus in resistance controlled by multiple loci (Tian et al., 2006; Skowrońska et al., 2020), the resistance locus BLMR2 confers a relative strong effect so the near isogenic lines showed the level of resistance which can meet the standard of blackleg resistance in Canada field trials (Canola Council of Canada).

\section{CONCLUSION}

The availability of accurate phenotypes and a large population aided in the precise mapping of the BLMR2 locus. With a combination of BLMR2 fine-mapping, molecular marker assisted development of NILs and comparative physical mapping, the candidate gene for BLMR2 as a homolog of CYP81F2 (At5g57220) in Arabidopsis was identified. Markers identified in this study can be used to transfer this horizontal resistance from cultivar to cultivar using MAS or gene pyramiding for resistance durability.

\section{DATA AVAILABILITY STATEMENT}

The datasets presented in this study can be found in online repositories. The names of the repository/repositories and accession number(s) can be found below: https://www.ncbi.nlm. nih.gov/, PRJNA378851.

\section{AUTHOR CONTRIBUTIONS}

QZ, HD, and GL designed the experiment and wrote the manuscript. QZ and HD finished the most experiments. MM, HL, 
ZL, and WX collected the data of some experiments. All authors contributed to the article and approved the submitted version.

\section{FUNDING}

This research was supported by the Natural Sciences and Engineering Research Council (NSERC) CRD project (CRDPJ 523840 - 18).

\section{REFERENCES}

Abdel-farid, I. B., Jahangir, M., Mustafa, N. R., van Dam, N. M., van den Hondel, C. A. M. J. J., Kyong, H., et al. (2010). Glucosinolate profiling of Brassica rapa cultivars after infection by Leptosphaeria maculans and Fusarium oxysporum. Biochem. Syst. Ecol. 38, 612-620. doi: 10.1016/j.bse.2010.07.008

Ansan-Melayah, D., Balesdent, M. H., Delourme, R., Pilet, M. L., Tanguy, X., Renard, M., et al. (1998). Genes for race-specific resistance against blackleg disease in Brassica napus L. Plant Breed. 117, 373-378. doi: 10.1111/j.1439-0523. 1998.tb01956.x

Becker, M. G., Zhang, X., Walker, P. L., Wan, J. C., Millar, J. L., Khan, D., et al. (2017). Transcriptome analysis of the Brassica napus-Leptosphaeria maculans pathosystem identified receptor, signaling and structural genes underlying plant resistance. Plant J. 90, 573-586. doi: 10.1111/tpj/.13514

Bednarek, P., Piślewska-Bednarek, M., Svatoš, A., Schneider, B., Doubský, J., Mansurova, M., et al. (2009). A glucosinolate metabolism pathway in living plant cells mediates broad-spectrum antifungal defense. Plant Cell 323, 101106. doi: 10.1126/science.1163732

Behla, R., Hirani, A. H., Zelmer, C. D., Yu, F., Fernando, W. G. D., McVetty, P., et al. (2017). Identification of common QTL for resistance to Sclerotinia sclerotiorum in three doubled haploid populations of Brassica napus (L.). Euphytica 213, 1-16. doi: 10.1007/s10681-017-2047-5

Brun, H., Chèvre, A. M., Fitt, B. D., Powers, S., Besnard, A. L., Ermel, M., et al. (2010). Quantitative resistance increases the durability of qualitative resistance to Leptosphaeria maculans in Brassica napus. New Phytol. 185, 285-299. doi: 10.1111/j.1469-8137.2009.03049.x

Chen, Y., and Fernando, W. G. D. (2006). Prevalence of pathogenicity groups of Leptosphaeria maculans in western Canada and North Dakota, USA. Can. J. Plant Pathol. 28, 533-539. doi: 10.1080/07060660609507331

Clay, N. K., Adio, A. M., Denoux, C., Jander, G., and Ausubel, F. M. (2009). Glucosinolate metabolites required for an Arabidopsis Innate immune response. Science 323, 95-101. doi: 10.1126/science.1164627

Dandena, H. B., Zhang, Q., Zhou, T., Hirani, A. H., and Liu, Z. (2019). Analysis of quantitative adult plant resistance to blackleg in Brassica napus. Mol. Breed. 124, 1-12. doi: 10.1007/s11032-019-1035-y

Dangl, J. L., and Jones, J. D. G. (2001). Defence responses to infection. Nature 411, $826-833$.

Delourme, R., Brun, H., Ermel, M., Lucas, M. O., Vallee, P., Domin, C., et al. (2008). Expression of resistance to Leptosphaeria maculans in Brassica napus double haploid lines in France and Australia is influenced by location. Ann. Appl. Biol. 153, 259-269. doi: 10.1111/j.1744-7348.2008.00258.x

Delourme, R., Chèvre, A. M., Brun, H., Rouxel, T., Balesdent, M. H., Dias, J. S., et al. (2006). Major gene and polygenic resistance to Leptosphaeria maculans in oilseed rape (Brassica napus). Eur. J. Plant Pathol. 114, 41-52. doi: 10.1007/ s10658-005-2108-9

Hayward, A., Mclanders, J., Campbell, E., Edwards, D., and Batley, J. (2012). Genomic advances will herald new insights into the Brassica: Leptosphaeria maculans pathosystem. Plant Biol. 14, 1-10. doi: 10.1111/j.1438-8677.2011. 00481.x

Kaur, S., Cogan, N. O. I., Ye, G., Baillie, R. C., Hand, M. L., Ling, A. E., et al. (2009). Genetic map construction and QTL mapping of resistance to blackleg (Leptosphaeria maculans) disease in Australian canola (Brassica napus L.) cultivars. Theor. Appl. Genet. 120, 71-83. doi: 10.1007/s00122-009-1160-9

\section{ACKNOWLEDGMENTS}

We would like to acknowledge Dilantha Fernando who offered most isolates used in this study.

\section{SUPPLEMENTARY MATERIAL}

The Supplementary Material for this article can be found online at: https://www.frontiersin.org/articles/10.3389/fpls.2021. 663868/full\#supplementary-material

Kutcher, H. R., Keri, M., McLaren, D. L., and Rimmer, S. R. (2007). Pathogenic variability of Leptosphaeria maculans in western Canada. Can. J. Plant Pathol. 29, 388-393. doi: 10.1080/07060660709507484

Larkan, N. J., Lydiate, D. J., Parkin, I. A. P., Nelson, M. N., Epp, D. J., Cowling, W. A., et al. (2013). The Brassica napus blackleg resistance gene LepR3 encodes a receptor-like protein triggered by the Leptosphaeria maculans effector AvrLm1. New Phytol. 197, 595-605. doi: 10.1111/nph.12043

Larkan, N. J., Lydiate, D. J., Yu, F., Rimmer, S. R., and Borhan, M. H. (2014). Colocalisation of the blackleg resistance genes Rlm2 and LepR3 on Brassica napus chromosome A10. BMC Plant Biol. 14:387. doi: 10.1186/s12870-014-0387-z

Larkan, N. J., Ma, L., and Borhan, M. H. (2015). The Brassica napus receptorlike protein $R \operatorname{lm} 2$ is encoded by a second allele of the LepR3/Rlm2 blackleg resistance locus. Plant Biotechnol. J. 13, 983-992. doi: 10.1111/pbi.12341

Larkan, N. J., Yu, F., Lydiate, D. J., Rimmer, S. R., and Borhan, M. H. (2016). Single R gene introgression lines for accurate dissection of the Brassica-Leptosphaeria pathosystem. Front. Plant Sci. 7:1771. doi: 10.3389/fpls.2016.01771

Li, G., and Quiros, C. F. (2001). Sequence-related amplified polymorphism (SRAP), a new marker system based on a simple PCR reaction: its application to mapping and gene tagging in Brassica. Theor. Appl. Genet. 103, 455-461. doi: $10.1007 / \mathrm{s} 001220100570$

Li, H., Barbetti, M. J., and Sivasithamparam, K. (2003). "Field isolates of Leptosphaeria maculans from Western Australia overcome a single dominant resistance gene in Brassica napus cv. Surpass 400," in Proceedings of the Thirteen. Bienn. Aust. Res. Assem. Brassicas. Proc. a Conf. Tamworth, New South Wales, Aust. 8-12 Sept. 2003, Tamworth, NSW, 134-135.

Long, Y., Wang, Z., Sun, Z., Fernando, D. W. G., McVetty, P. B. E., and Li, G. (2011). Identification of two blackleg resistance genes and fine mapping of one of these two genes in a Brassica napus canola cultivar "Surpass 400.". Theor. Appl. Genet. 122, 1223-1231. doi: 10.1007/s00122-010-1526-Z

Maeda, H., Matsushita, K., Iida, S., and Sunohara, Y. (2006). Characterization of two QTLs controlling resistance to rice stripe virus detected in a Japanese upland rice line, Kanto 72. Breed. Sci. 56, 359-364. doi: 10.1270/jsbbs. 56.359

Mesterhazy, A. (2020). Updating the Breeding Philosophy of Wheat to Fusarium head blight (FHB): resistance components, QTL identification, and phenotyping-a review. Plants 9:1702. doi: 10.3390/plants9121702

Raman, H., Raman, R., and Larkan, N. (2013). Genetic dissection of blackleg resistance loci in rapeseed (Brassica napus L .). Plant Breed. Lab. Fields 4, 85-120. doi: 10.5772/53611

Raman, R., Taylor, B., Marcroft, S., Stiller, J., Eckermann, P., Coombes, N., et al. (2012). Molecular mapping of qualitative and quantitative loci for resistance to Leptosphaeria maculans causing blackleg disease in canola (Brassica napus L.). Theor. Appl. Genet. 125, 405-418. doi: 10.1007/s00122-012-1842-6

Rimmer, S. R. (2006). Resistance genes to Leptosphaeria maculans in Brassica napus. Can. J. Plant Pathol. 297, 288-297.

Robin, A. H. K., Yi, G.-E., Laila, R., Hossain, M. R., Park, J.-I., Kim, H. R., et al. (2017). Leptosphaeria maculans alters glucosinolate profiles in blackleg diseaseresistant and -susceptible cabbage lines. Front. Plant Sci. 8:1769. doi: 10.3389/ fpls.2017.01769

Rouxel, T., Penaud, A., Pinochet, X., Brun, H., Gout, L., Delourme, R., et al. (2003). A 10-year survey of populations of Leptosphaeria maculans in France indicates a rapid adaptation towards the $R \operatorname{lm} 1$ resistance gene of oilseed rape. Eur. J. Plant Pathol. 109, 871-881. doi: 10.1023/A:1026189225466 
Skowrońska, R., Mariańska, M., Ulaszewski, W., Tomkowiak, A., Nawracała, J., and Kwiatek, M. T. (2020). Development of triticale $\times$ wheat prebreeding germplasm with loci for slow-rusting resistance. Front. Plant Sci. 11:447. doi: 10.3389/fpls.2020.00447

Sprague, S. J., Balesdent, M. H., Brun, H., Hayden, H. L., Marcroft, S. J., Pinochet, $\mathrm{X}$., et al. (2006). Major gene resistance in Brassica napus (oilseed rape) is overcome by changes in virulence of populations of Leptosphaeria maculans in France and Australia. Eur. J. Plant Pathol. 114, 33-40. doi: 10.1007/s10658-0053683-5

Tian, Z. D., Liu, J., Wang, B. L., and Xie, C. H. (2006). Screening and expression analysis of Phytophthora infestans induced genes in potato leaves with horizontal resistance. Plant Cell Rep. 25, 1094-1103. doi: 10.1007/s00299006-0169-7

Van Berloo, R., Aalbers, H., Werkman, A., and Niks, R. E. (2001). Resistance QTL confirmed through development of QTL-NILs for barley leaf rust resistance. Mol. Breed. 8, 187-195. doi: 10.1023/A:1013722008561

Wiesner, M., Hanschen, F. S., Schreiner, M., Glatt, H., and Zrenner, R. (2013). Induced production of 1-methoxy-indol-3-ylmethyl glucosinolate by jasmonic acid and methyl jasmonate in sprouts and leaves of pak choi (Brassica rapa ssp. chinensis). Int. J. Mol. Sci. 14, 14996-15016. doi: 10.3390/ijms140714996

Yu, F., Gugel, R. K., Kutcher, H. R., Peng, G., and Rimmer, S. R. (2013). Identification and mapping of a novel blackleg resistance locus LepR4 in the progenies from Brassica napus $\times$ B. rapa subsp. sylvestris. Theor. Appl. Genet. 126, 307-315. doi: 10.1007/s00122-012-1919-2

Yu, F., Lydiate, D. J., and Rimmer, S. R. (2005). Identification of two novel genes for blackleg resistance in Brassica napus. Theor. Appl. Genet. 110, 969-979. doi: 10.1007/s00122-004-1919-y
Yu, F., Lydiate, D. J., and Rimmer, S. R. (2008). Identification and mapping of a third blackleg resistance locus in Brassica napus derived from B. rapa subsp. sylvestris. Genome 51, 64-72. doi: 10.1139/g0 7-103

Zhang, X., Peng, G., Kutcher, H. R., Balesdent, M. H., Delourme, R., and Fernando, W. G. D. (2016). Breakdown of Rlm3 resistance in the Brassica napusLeptosphaeria maculans pathosystem in western Canada. Eur. J. Plant Pathol. 145, 659-674. doi: 10.1007/s10658-015-0819-0

Zhou, T., Xu, W., Hirani, A. H., Liu, Z., Tuan, P. A., and Elliott, C. (2019) Transcriptional insight into Brassica napus resistance genes LepR3 and Rlm2 mediated defense response against the Leptosphaeria maculans infection. Front. Plant Sci 10:823. doi: 10.3389/fpls.2019.00823

Zhu, J. S., Struss, D., and Röbbelen, G. (1993). Studies on resistance to phoma lingam in Brassica napus-Brassica nigra addition lines. Plant Breed. 111, 192 197. doi: 10.1111/j.1439-0523.1993.tb00629.x

Conflict of Interest: The authors declare that the research was conducted in the absence of any commercial or financial relationships that could be construed as a potential conflict of interest.

Copyright (c) 2021 Zhang, Dandena, McCausland, Liu, Liu, Xu and Li. This is an open-access article distributed under the terms of the Creative Commons Attribution License (CC BY). The use, distribution or reproduction in other forums is permitted, provided the original author(s) and the copyright owner(s) are credited and that the original publication in this journal is cited, in accordance with accepted academic practice. No use, distribution or reproduction is permitted which does not comply with these terms. 